\section{Wealden Geology}

Geology of the Country around Royal Tunbridge Wells. (Memoirs of the Geological Survey of Great Britain, England and Wales.) By C. R. Bristow and R. A. Bazley. With contributions by R. W. Gallois, E. R. ShephardThorn, R. Allender, R. Casey and H. C. Ivimey-Cook. Pp. $\mathrm{x}+161$ (9 plates). (HMSO: London, November 1972.) £2.

THE memoir is an explanation of Oneinch Geological Sheet 303, New Series, which was resurveyed in 1960-1965 and published in 1971. The area is centrally situated in the Wealden Basin, and at outcrop the solid rocks are almost all of Wealden age with a very small area of Purbeck strata in the extreme southeast. The memoir includes an account of the stratigraphical palaeontology of Jurassic strata penetrated by the Ashdown boreholes, one of which terminated in undated, pre-Jurassic sediments.

After an introductory section, the remaining seven chapters deal with structure, concealed formations, the Jurassic, the Cretaceous, the Pleistocene and Recent deposits, superficial structures and economic geology. Each chapter is composed of individual (initialled) paragraphs by the field surveyors and specialist contributors, which generally fit together well to give a thorough account of the area. An anomaly arises because of the unfortunate use of "Jurassic" and "Cretaceous" as chapter headings: the Purbeck Beds are discussed under the Jurassic despite the apparent acceptance of Casey's views on the age of these beds.

Of the eight chapters, that on the Cretaceous (Wealden Beds) occupies seventy-one out of the 123 relevant pages. There is a general account of the Hastings Beds Group, which is divided into five mappable formations (the term "formation" in parentheses). These represent the deposits of three major cyclothems of deltaic sedimentation. Ostracods provide the most useful zonal fossils, and F. W. Anderson has recognised three Cypridea zones. Field mapping indicates that certain stratigraphical names, including "Fairlight Clays", should be abandoned.

Detailed description of Wealden sections occupies fifty-four pages. This contrasts with the brevity of the chapters on superficial structures and on economic geology, which together occupy seventeen pages. For the section on superficial structures a sketch map to illustrate areas prone to surface movement (landslipping, cambering and valley bulging) would have been useful. The chapter on economic geology consists of brief accounts of past and present working for material such as Wealden iron, brick-clay, cement and lime, building stones and oil and gas.
As such it is an interesting historical survey but of limited present day significance. Sand and gravel, for example, are discussed in three short paragraphs, despite the extensive areas of outcrop of sandy formations. Although "no large commercial organisations are utilising this source of sand at present, probably because the sand is too fine for most purposes", an assessment of possible industrial uses, or even of reserves, would be invaluable.

In summary, the authors have produced a good and attractive memoir within the limitations imposed by the standard framework of the sheet memoir series. One is left wondering for whom the Institute of Geological Sciences produces these publications, which have evolved so little in style and content. With the increased emphasis on mineral assessment and other aspects of economic geology within the institute, it could be useful to expand the economic side of the memoirs, possibly at the expense of detailing innumerable local sections.

P. F. RAwSON

\section{Adventurous Physics}

Forces and Particles: An Outline of the Principles of Classical Physics. By A. B. Pippard. Pp. xii +321. (Macmillan: Basingstoke and London, November 1972.) $£ 5.75$.

Professor Pippard explains in the preface that this book is an expanded version of his lectures to the "fast" stream of first year physics students in Cambridge. He refers to them as "those who wanted the more searching treatment", but certainly in my time the two courses which ran in parallel were referred to as "fast" and "slow". These are relative terms; to quote again from the author's preface, "Recognizing the impossibility of pleasing everyone, I have now addressed myself, as I did when giving the course, to the more adventurous who are prepared to work out for themselves congenial patterns of thought that will make sense of what can so easily remain a disorderly assembly of observations and ideas". This is not, therefore, a book for the average student, and it will not make a fortune for its publisher or its author. It is, however, distinctly possible that it will be an influential book, and it should be read by every physics lecturer, for we are in some danger of forgetting that these topics can be treated with this degree of elegance, economy and clarity.

The coverage is not as wide as the subtitle might suggest; it is restricted to dynamics and electricity and magnetism with brief incursions into relativity and introductory quantum mechanics. A few selected experiments are described in some detail. The order in which topics are treated is on the whole not unconventional. I found only one point at which I felt the book departed from the high standard of exposition and logical treatment which characterizes it ; this is on page 194 where $D$ makes a sudden appearance in circumstances where it might be confused with a depolarizing coefficient $D$, to disappear incidentally after the following page and find no mention in the chapter entitled "Maxwell's displacement hypothesis". There are some characteristically Pippardian asides on topics such as numerology. God, like $D$, is briefly admitted to a possible role (page 130) but is not in the index.

Altogether this is an excellent book in the best traditions of the Cavendish.

W. COCHRAN

\section{A Modern Icarus}

Flight and Nature. By M. W. Saunders, Second edition. Pp. vi+126. (M. W. Saunders: Chaldon, Surrey, 1972.) $£ 4.80$.

IN a book largely concerned with a theoretical synthesis of man-powered ornithopters, it is strange to find an introduction reiterating all the usual statements on man's ecological responsibilities, however valid such statements may be. The author seems to feel that the study of natural flight is a duty, though be has apparently made no investigations himself. As he puts it: "The main reason for studying ornithoptics and aero-ecology concerns the long term maintenance of our heritage. A broad and continuous investigation would seem appropriate". He also suggests that there is a "likelihood of beneficial offshoots concerning such matters as birdstrikes, aerodynamics, air traffic, etc.". It seems that the author believes that little is known about the flight of birds. His list of references makes no mention of some of the most valuable recent contributions.

The theoretical study is straightforward, though perhaps oversimplified in parts; but where he considers aspects of practical design the proposals are very questionable. There seems to be no realisation of the stresses on the structure, hinge joints, and so on, due to inertial loads. Frictional losses within the mechanism are dismissed; power transfer is supposed to be carried out by wires which the author says must be designed "to have a very low sliding friction. For example, they may slide in guide tubes and be supported: by a fluid medium, by rollers, or by coaxial springs". His proposals for instrumentation are even more obscure: "Information on the craft's performance could be conveyed to the aviator by means of earphones, such information could be verbal, or in the form of sounds related directly with performance. 